\title{
UMA SOCIOLOGIA DA LITERATURA NA OBRA DE ANTONIO CANDIDO
}

Ubiratã Souza

RESUMO: A trajetória longeva e altamente investigativa de Antonio Candido não poderia ter produzido e não produziu conceitos teóricos fechados e coesos, verificáveis de igual modo em toda a sua produção, e que, portanto, possam ser descolados dos objetos empíricos dos quais ele lança mão e aplicados a esmo a quaisquer outros contextos. Para discutir esse pressuposto analisamos momentos distintos da sua trajetória através de três estilos distintos de sua produção cunhados por ele próprio: um ensaio "empenhado teoricamente", uma "crítica esquemática" e uma "crítica histórica" e buscamos analisar os diversos valores e funcionalidades que o termo "sociedade" assume em função de objetos específicos desses diferentes estilos de ensaios.

PALAVRAS-CHAVE: Crítica sociológica; sociologia da literatura; Antonio Candido.

ABSTRACT: The Antonio Candido's intellectual trajectory fruitful, extremely long-lived and highly investigative could not have produced and not produced closed theoretical concepts and cohesive, verifiable equally in all their production, and therefore, can be taken off of the empirical objects of which it spear hand and applied haphazardly to any other contexts. To discuss this proposition, this article analyze different moments of its history through three distinct styles of production minted by himself: an essay "committed in theory," a "schematic critical" and "historical criticism" and we analyze the various values and features that term "society" takes on according to specific objects of these different types of essay.

KEYWORDS: Sociological criticism; sociology of literature; Antonio Candido. 
o ano de 2009, o Departamento de Teoria Literária e Literatura Comparada (DTLLC) da Faculdade de Filosofia, Letras e Ciências Humanas (FFLCH) da USP dedicou dois números da sua revista Literatura e sociedade em homenagem à obra e à persona acadêmica de Antonio Candido. Numa seção inicial de entrevistas, três perguntas foram submetidas a diversas personalidades intelectuais do Brasil e da América Latina. Roberto Schwarz foi um dos entrevistados e, à primeira pergunta, única que aqui nos interessa ("Quais os conceitos que consideraria centrais e mais fecundos na obra crítica e historiográfica de Antonio (andido?"), responde de modo arguto, praticamente adequando a formulação da pergunta à sua perspectiva para observar a obra de Candido. Roberto Schwarz insiste que a obra do professor foge à rigidez de formulações estanques a respeito de conceitos, teorias e métodos. Segundo Schwarz (2009, p. 54):

No seu trabalho, a acuidade estética e a reflexão histórica pesam mais que a teoria abstrata, a qual qualificam segundo a circunstância. Sem prejuízo da bibliografia atualizada, a relação independente com as inovações conceituais de Europa e América do Norte é um dos segredos da sua inteligência crítica. Contrariando os nossos hábitos novidadeiros, ele as submete à verificação da experiência cultural acumulada no país, que não é posta de lado, ou melhor, que é valorizada como um fator de conhecimento.

O que resultaria dessa submissão da influência teórica do Norte global à verificação local prévia na obra do prof. Candido seria justamente o que Schwarz chama de "desajuste" entre as tendências hegemônicas e a "matéria brasileira"; esse desajuste entre a dimensão local verificável na sociedade brasileira e o influxo das ideias que circulam a partir da Europa, a propósito, é caro para Schwarz, que já teria discorrido longamente sobre esse assunto em célebre ensaio (SCHWARZ, 2012, p.11-31). Insistir nesse ponto relativo a Antonio Candido é propor, precisamente, que sua obra não seja especificamente teórica antes 
de ser qualificadamente analítica e interpretativa, que realiza a sua colheita diretamente no dado empírico privilegiando a observação à formulação de abstrações epistemológicas. No caso específico de seu trabalho como crítico literário, a análise das construções e articulações estéticas - ou "formais", como sói preferir - tem privilégio diante das formulações teóricas de como uma práxis crítica deva se sustentar ou não. Schwarz está seguro em afirmar em sua entrevista que o principal discurso do método de Candido está justamente naquela poética do ensaio contida na sua prática crítica: "o roteiro dos ensaios, com suas etapas muito diversas, cujo encadeamento é sempre uma surpresa, talvez seja mais elucidativo do que a indicação dos conceitos principais" (SCHWARZ, 2009, p. 55).

Trata-se de uma visão desafiadora acerca da obra do prof. Candido, sobretudo quando se considera que se consagrou a respeito do seu nome a imagem de "historiador" e "teórico" da literatura brasileira, pechas que ele nunca fez questão de sustentar. A consagração de improváveis rótulos acerca da obra de Candido ad aperturam libri, a propósito, é representativa da manifestação das diversas recepções distintas que seus escritos obtiveram em âmbitos variados, sintoma de que sua produção, para além de sua própria autonomia e problemáticas específicas, pode eventualmente ser usada para preencher traumáticos hiatos teóricos e historiográficos no quadro da pesquisa literária, cenário este que o Brasil ainda hoje conserva. Em outras palavras, diante da azáfama causada pela ausência de algum grande teórico brasileiro das literaturas, utiliza-se seu mais representativo e longevo crítico como tal. Para tanto, categoriza-se aparatos instrumentais de sua

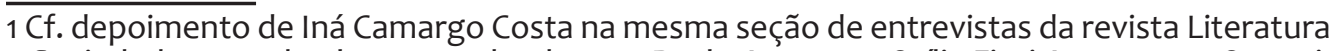
e Sociedade, quando ela, concordando com Paulo Arantes e Otília Fiori Arantes em O sentido da formação (1997), inscreve Formação da literatura brasileira de Antonio Candido (2013) num repertório maior do ensaísmo brasileiro com o objetivo de "interpretação do Brasil”, o que o excluiria da categoria específica de "historiografia literária". Segundo Costa, categorizar a Formação da literatura brasileira como historiografia literária está a serviço de "meIhor criticá-la por aquilo que ela não é", e torna-se categórica: "Antonio Candido não tem obra historiográfica, pelo menos não no sentido usual” (COSTA, 2009, p. 42). Ao afirmar que Candido "não tem" obra historiográfica, Iná Camargo Costa decerto não considera os três volumes de Presença da literatura brasileira: história e antologia, que Candido publica em coautoria com José Aderaldo Castello a partir de 1964. 
crítica como abstrações teóricas, submetendo-os à cristalização e ao estancamento em detrimento da eficácia de sua fluidez circunstancial.

É necessário aqui fazer uma alarmante ressalva. O fato de que a obra de Antonio Candido está especificamente detida em análises empíricas do literário, a despeito de conceituações e abstrações teóricas, não deve estar em prejuízo da imensa coerência que apresenta e de um fito total que persegue, bem definida pela expressão-locução janiforme "literatura e sociedade", tão recorrente em tudo o que escreve. Considerar que o peso das abstrações teóricas e conceitos esteja qualificado estritamente ao sabor das circunstâncias críticas não torna obsoleto o fato de que qualquer prática crítica alimenta em seu fundo uma articulação epistemológica, um horizonte final que permite perscrutar a obra em vistas da sua síntese e da compreensão total, o que, a propósito, no trabalho de Antonio Candido, só pode ser realizado se estivermos pari passu de uma compreensão igualmente articulada da sociedade. Essa "economia crítica", para emular expressão cara ao crítico, entre literatura e sociedade é de compreensão metodológica muito mais complexa do que podem talvez sugerir a singeleza e linguagem límpida e ordinária que ele tão bem emprega em gentileza ao leitor.

Com efeito, a própria trajetória de Antonio Candido há de revelar que sua afinidade com a sociologia deriva de sua primeira formação, no ano de 1941, nas primeiras turmas de sociologia da Faculdade de Filosofia, Ciências e Letras da Universidade de São Paulo. Em 1942 foi convidado a se tornar professor da Cadeira de Sociologia II, então assumida por Fernando Azevedo. Entre 1947 e 1954 Antonio Candido desenvolve pesquisa intitulada Os parceiros do Rio Bonito, que representaria o núcleo central de sua produção escrita relativa à sociologia e sua tese de doutorado em ciências sociais (CANDIDO, 2010, p. 12-13). Em Os parceiros do Rio Bonito, Candido empreende uma análise da figura social do caipira desde sua composição durante a colonização paulista, no decurso do avanço do capitalismo comercial europeu, até as suas configurações contemporâneas. Interessa à pesquisa socioló- 
gica de Candido, precisamente, de que modo essa configuração cultural do caipira arranjou-se e rearranjou-se em relação à penetração das novas formas de economia no ambiente rural de São Paulo desde o final do século XIX. Implodida em suas bases configuradas a partir dos "mínimos vitais" e de economia fechada (Ibid., p. 45-56) com a introdução do latifúndio de monocultura de exportação, a cultura caipira do interior do Estado de São Paulo encontra no sistema da parceria uma condição econômica que lhe permite uma "redefinição dos incentivos tradicionais, por meio do ajustamento dos velhos padrões ao novo contexto social" (Ibid., p. 232). O avanço cada vez mais sensível da economia urbana e crescente industrialização do país, no entanto, se apresentavam como novos fatores de desagregação e desestabilização da cultura caipira no presente da pesquisa do sociólogo. Pelo que se vê:

De fato, a situação atual é a do caipira entregue aos seus miseráveis recursos, adaptando-se penosamente a uma situação nova e vertiginosa de mudança, por meio de técnicas materiais e sociais que tinham sido elaboradas para uma situação geral desaparecida. Encarada deste ponto de vista, dentro do processo de urbanização e industrialização, a regressão adaptativa, possibilitada pela latência cultural, exprime uma situação da mais revoltante iniquidade (CANDIDO, 2010, p. 256-257).

No ano de 1954 Os parceiros do Rio Bonito é recebido como requisito para a titulação de doutoramento em ciências sociais de Antonio Candido, mas o trabalho, curiosamente, só é publicado dez anos depois. Segundo o próprio Candido, o escrito teria sido "deixado de lado, na esperança de poder melhorá-lo e ampliá-lo" (Ibid., p. 13), o que ele não teria feito, motivo pelo qual a tese ganhou sua publicação em livro do modo como foi apresentada à banca. Os parceiros do Rio Bonito, tomado como núcleo central da produção sociológica de Antonio Candido, revela o entrecruzamento de diversas tendências do ambiente intelectual brasileiro à época, o que o faz aumentar o espectro de sua 
relevância (JACKSON, 2009, p. 75). A influência da sociologia conforme desenvolvida no Brasil pelos professores franceses no ambiente de formação da Faculdade de Filosofia, Ciências e Letras da USP é significativa. Entre esses professores franceses, Roger Bastide transmite a Antonio Candido algumas características que terão implicações posteriores no seu método de escrita. A influência de Roger Bastide ${ }^{2}$ sobre o trabalho de Antonio Candido revela-se, sobretudo, pelo primado da observação da "realidade" como princípio do trabalho analítico, acrescida de uma abertura teórica ampla, livre de dogmatismos de escola ${ }^{3}$. Além disso, destaca-se um interesse crescente em observar camadas mais excluídas do processo geral da sociedade, como a cultura dos negros no Brasil, no caso de Bastide, e interesse pelo caipira em processo de aculturação no estado de São Paulo, no caso de Candido (JACKSON, 2002, p. 38-39). Para além da influência dos franceses, no entanto, é possível observar um contato muito grande com a tradição do ensaísmo brasileiro, o que conectará a articulação de problemas próprios da afirmação da sociologia enquanto disciplina no Brasil às tendências de interpretação abrangente da sociedade brasileira face aos processos então definidos como "formação" ou "modernização" (JACKSON, 2009, p. 75).

Paralela à carreira de Antonio Candido como sociólogo, desenvolvia-se a sua atuação junto ao grupo da revista Clima, o que contribuiria

2 É digna de nota a definição que Antonio Candido faz do estilo crítico de Roger Bastide, que transcrevemos a seguir; ao analisar o estilo de escrita do intelectual francês, Candido parece descrever o seu próprio estilo crítico, ou ao menos, de modo irônico, mostrar que alimenta certa afiliação ao ensaísmo francês do qual Bastide foi representante no Brasil durante sua estadia aqui. A ver: "Para descobrir esses lençóis ocultos, [Bastide] procura o que se poderia chamar as melhores 'entradas' no texto. Mas de um modo aparentemente espontâneo, como se estivesse dizendo coisas que todos poderiam dizer - marca de urbanidade crítica própria da tradição francesa, que procura (ou melhor, procurava) disfarçar ao máximo a erudição, dissolvendo na tonalidade ensaística o peso da informação e abstração dos princípios teóricos" (CANDIDO, 1997, p. 14). Seria importante notar (o que, infelizmente, não está em causa aqui) quanta afinidade pode haver entre a tradição do ensaísmo francês e o ensaísmo brasileiro da década de 1930, e como Antonio Candido, formado na fronteira entre ambas, apropria-se das diversas correntes para construção de um estilo próprio e característico de linguagem.

3 Cite-se o fato de uma das principais críticas contrárias à tese de doutoramento ter sido o fato de Candido utilizar-se de teóricos "muito díspares”, como Marx da Ideologia alemã, Malinowski, Audrey Richards, Lévi-Strauss, Redfield, cf. Jackson, 2002, p. 51. 
para o desenvolvimento de sua produção como crítico literário. Fundada em 1941 pelo "mecenas" Alfredo de Mesquita (que desde o início da década de 1930 empreendia esforços para renovação do teatro brasileiro, sobretudo a partir da crítica) e Lourival Gomes Machado (que alimentava o desejo de criar uma revista junto ao próprio Antonio Candido), a revista Clima congregou ao redor de si um conjunto de alunos da Faculdade de Filosofia, Ciências e Letras que passariam a se destacar no ambiente cultural e intelectual da São Paulo dos anos de 1940: Paulo Emílio Salles Gomes, Décio de Almeida Prado, Rui Coelho, Lourival Gomes Machado, Gilda de Mello e Souza, entre outros. Foi justamente a partir de Clima que os jovens universitários passariam a definir as vertentes temáticas do trabalho que, por princípio, mostrava-se estritamente crítico - essa definição acompanhou a divisão do trabalho consoante às seções permanentes que a revista teve: Antonio Candido seria responsável pela seção de literatura, Lourival Gomes Machado pela de artes plásticas, Paulo Emílio Salles Gomes pela de cinema, Décio Almeida Prado pela de teatro, entre outros permanentes e demais colaboradores, entre os quais incluía-se Gilda de Mello e Souza (PONTES, 1998, p. 97-99).

A geração que acabou se firmando ao redor de Clima caracterizou um novo momento da intelectualidade brasileira, constituindo-se por contraste ou continuidade em relação às anteriores. Se por um lado se afastavam da geração do modernismo de 1922, essencialmente pelo seu caráter crítico funcional ao invés da produção artística demolidora, por outro lado aproximavam-se de 1922 e da subsequente geração de 1930 no intuito de aprofundar o conhecimento do Brasil e de sua composição histórica e social híbrida, plural e desigual. Outrossim, se se aproximavam da geração de 1930 por terem a compreensão da história e formação da sociedade e cultura brasileira no horizonte, afastavam-se dessa geração ao abandonarem as grandes narrativas teleológicas de formação de um Brasil "total" para aterem-se sobre aspectos específicos emblemáticos que funcionassem como metonímia do processo geral (ARRUDA, 1995, p. 131), agora analisados através de apara- 
tos teóricos e epistemológicos das disciplinas científicas e universitárias constituídas no cenário de criação da FFCL - USP (PONTES, 1998, p. 58-60). Esse pendor crítico, analítico e funcional da "geração Clima" estaria, claro, em choque com as gerações anteriores, causando um misto de estranhamento, hostilidade ou mesmo aderência com aqueles antigos homens da cultura. É justamente por conta deste cenário que Oswald de Andrade, nas muitas polêmicas que estabelecia com tudo e com todos 4 , teria alcunhado a nova geração dos "moços" de "chato-boys", episódio absolutamente emblemático do contraste entre as gerações, segundo analisa Heloísa Pontes:

A introdução de novas maneiras de conceber e praticar o trabalho intelectual, promovida por essa instituição [a Universidade de São Paulo] e atualizada por seus integrantes, chocava-se com o padrão dominante das carreiras intelectuais da época, construídas na intersecção do jornalismo, da política, da literatura e da vida mundana. Oswald não foi o único, portanto, a manifestar sentimentos ambivalentes - da recusa, desconfiança, ressentimento, surpresa e admiração - diante da mentalidade universitária, especializada e profissional que estava sendo construída no período, por meio da presença dos professores estrangeiros e da atuação da nova geração de críticos de cultura - "a novíssima", como queria Milliet - oriunda da Faculdade de Filosofia, Ciências e Letras (PONTES, 1998, p. 89).

Esse ambiente intelectual tão característico determinou a construção, desde Clima, de uma abordagem específica da literatura que passaria a ser empreendida por Antonio Candido, que uniria, a um só tempo, sua formação sociológica, sua vocação literária, e sua complei-

4 Cf. a recepção crítica de Candido que se empenhou em desanuviar a obra de Oswald de Andrade da polêmica desde o início da carreira: "Estouro e libertação" (In: Candido, 1992, p. 17-32); e também, já quando estava consagrado como acadêmico de literatura: "Esquema sentimental de Oswald de Andrade” (In: Candido, 1970, p. 57-122). Cf. também a reverberação da crítica de Candido em outra (inevitável) polémica com Oswald in: Pontes, 1998, p. 77-83. 
ção de "espírito de geração". Heloísa Pontes, em análise da produção de Candido contida em Clima, avalia que sua originalidade crítica está conectada a certa insatisfação e à necessidade de abandono de uma crítica passadiça, biografista (quando não viciada num positivismo determinista) e impressionista, que até então havia operado, e encontrava-se igualmente a par de uma modificação geral dos estudos literários a partir da década de 1940, que, no Brasil, assomou-se ao definitivo ingresso da literatura no âmbito universitário, que contou com a força, no Brasil, de nomes como Afrânio Coutinho, Álvaro Lins, e com a chegada por ocasião da guerra do austríaco Otto Maria Carpeaux (Heloísa Pontes não cita, mas seria necessário incluir aqui também a presença de Anatol Rosenfeld, alemão, e Paulo Rónai, húngaro, Ibid., p. 100-101). Ainda segundo Pontes, ao tentar suplantar a antiga crítica, Candido investiria em um novo exercício analítico que buscaria investigar "as ligações profundas" que um autor mantém com seu tempo e com a sociedade, o que serviria para situar a obra tanto socialmente quanto culturalmente.

Com efeito, a partir de 1943 Antonio Candido passaria a escrever semanalmente para o jornal Folha da Manhã fazendo o tal "rodapé literário", atividade que desenvolveria até 1947. Esse seria o primeiro passo para a profissionalização de Candido como crítico literário, que, de fato, pleiteou vaga para literatura junto à FFCL-USP em 1945, num polêmico ${ }^{5}$ concurso em que teria concorrido com o próprio Oswald de Andrade, Sousa Lima (que era professor interino) e Cerqueira Leite (assistente da cadeira). Se não conseguiu sua aprovação, obteve com o concurso sua livre-docência, e resultou do processo a publicação Introdução ao método crítico de Sílvio Romero, que fez vir a público em edição própria no mesmo ano de 1945 (DANTAS, 2002, p. 22). A "indefinição" da carreira de Candido, pendulando entre a sociologia e a literatura, permaneceria até 1958, quando ele iria para Assis para

5 Segundo depoimento de Décio Almeida Prado, a reprovação de Candido no concurso era "incrível”, porque, uma vez "empatado" com Sousa Lima, o Conselho Universitário teria decidido pelo concorrente e não por Candido, o que teria gerado uma situação esdrúxula: "ele ficou em segundo, com média mais alta" (JACKSON, 2002, p. 43). 
a fundação da Faculdade de Filosofia, Ciências e Letras de Assis, que seria anexada à Universidade Estadual Paulista em 1976. A partir daquele momento, Candido se tornaria definitivamente um profissional das letras, e não mais das ciências sociais. Em 1961, Candido retornaria à sua alma mater, ocupando a recém-criada Cadeira de Teoria Literária e Literatura Comparada, que daria origem à criação do departamento homônimo ainda hoje em profícua atividade.

Em 1965 Antonio Candido, com repertório significante de sua produção crítica publicada em livros e periódicos ${ }^{6}$, lança Literatura e sociedade: estudos de teoria e história literária (2008), contrariando a sua tendência geral de elaboração de estudos críticos, que anteriormente só haviam perdido espaço para sua produção sociológica. No primeiro capítulo desta coletânea de ensaios, intitulado "Crítica e sociologia (tentativa de esclarecimento)", Candido elabora formulações preciosas sobre como concebe muito de sua prática crítica, que seriam utilizadas costumeiramente como síntese de todo seu processo crítico - não raro até mesmo submetidas ao processo de cristalização a que se aludiu acima. No prefácio inserido na terceira edição da coletânea, Candido define o ensaio referido num conjunto dos "mais empenhados teoricamente". Para o autor, neste conjunto estavam formulações que abrangiam uma problemática: a dependência que a compreensão da funcionalidade de uma obra mantém em relação à "realidade social" transformada em "componente de uma estrutura literária" (CANDIDO, 2008, p. 9).

No ensaio propriamente dito, há desde suas primeiras linhas a proposição de uma equação crítica dual que se debate acerca de se compreender a literatura com recurso a outra ordem de fatores, como em "literatura e sociedade", a propósito. No entanto, os termos da 6 Até 1965, Antonio Candido já teria publicado os seguintes livros de crítica literária (sem contar artigos em periódicos e a produção sociológica): Introdução ao método crítico de Sílvio Romero, em 1945 ( $2^{\text {a }}$ ed. em 1963); Ficção e confissão: estudo sobre a obra de Graciliano Ramos, em 1956; Formação da literatura brasileira: momentos decisivos, em 1959 ( $2^{\text {a }}$ ed. em 1964); O observador literário, em 1959; A personagem de ficção, (em parceria com Paulo Emílio Salles Gomes, Décio de Almeida Prado e Anatol Rosenfeld) em 1963; Presença da literatura brasileira: história e antologia, v. 1, 2, 3 (com José Aderaldo Castello), em 1964; Tese e antítese, em 1964, cf. Dantas, 2002 p. 21-36. 
equação são todos flutuantes, irmanados que estão de diversos outros termos cambiáveis que ocupam as mesmas posições no interior da equação sem prejuízo do valor conceitual, teórico ou epistemológico, a saber: "obra e ambiente", "obra e aspecto da realidade", "texto e contexto" (Ibid., p. 14), "interno e externo", "estrutura da obra e elemento histórico-social", "forma e elemento sociológico" (estes dois últimos emprestados de Lukács, ibid., id.), "organização interna e fator social", enfim. Entre os diversos momentos da história da crítica que enfatizariam um dos fatores da equação como o mais preeminente na análise da obra, a partir do qual a literatura explicar-se-ia tão somente, Candido procura encontrar um ponto de equilíbrio entre as duas posições. Para isso, concebe a obra como um todo objetivo e autônomo, composto por um texto, por uma estrutura, com desenvolvimento "interno", e uma "organização interna"; do mesmo modo, concebe igualmente uma dimensão alheia ao texto, eventualmente qualificada como "ambiente", ou um "aspecto da realidade" (não-literária, portanto), ou um "contexto" "externo". A equação fica mais complexa quando essa realidade não-literária objetiva passa a ser definida no ensaio através de disciplinas acadêmicas cientificamente constituídas, a começar pelo próprio título do ensaio: sociologia, "elemento sociológico", ou "elemento histórico-social". De modo um tanto ardiloso, indaga-se: ao realizar este câmbio entre os termos correlatos à realidade objetiva, substituídos por disciplinas acadêmicas, não repousa no âmago desta opção uma sugestão de que são aquelas disciplinas que trabalham efetivamente com a desejada realidade objetiva tangível enquanto a crítica literária, voltada à primeira posição da equação, cuida especificamente do irreal, do fantasioso, do alheio à história e à sociedade?

Observando de modo plácido e insatisfeito o pêndulo da história da crítica literária que ora oscila para a "realidade objetiva", ignorando a estética e as questões formais, ora oscila para o "interno autônomo", ignorando que haja um mundo ao redor do livro, Candido encontra seu ponto de equilíbrio, pressentindo que há qualquer coisa de solúvel nos 
ingredientes da equação, prevendo a existência de uma "diversidade coesa do todo" (Ibid., p. 17):

Neste caso, saímos dos aspectos periféricos da sociologia, ou da história sociologicamente orientada, para chegar a uma interpretação estética que assimilou a dimensão social como fator de arte. Quando isto se dá, ocorre o paradoxo assinalado inicialmente: o externo se torna interno e a crítica deixa de ser sociológica, para ser apenas crítica. O elemento social se torna um dos muitos que interferem na economia do livro, ao lado dos psicológicos, religiosos, linguísticos e outros. Neste nível de análise, em que a estrutura constitui o ponto de referência, as divisões pouco importam, pois tudo se transforma para o crítico, em fermento orgânico de que resultou a diversidade coesa do todo.

O apelo a esse dado externo concebido como uma realidade objetiva alheia ao texto faz a formulação teórica de Candido ganhar ares realistas. Talvez por um irônico acaso (ou não) a presença de Lukács se faça sentir no início do texto7. Há que se lembrar, no entanto, toda a extrapolação crítica que, em nome do empenho da obra a uma realidade urgente que deveria ser retratada à exaustão, havia feito o pêndulo da história da crítica tocar seus mais remotos pontos no sentido da realidade. Refiro-me precisamente ao realismo socialista e suas doutrinas derivadas da crítica literária de orientação marxista; definições totalmente conteudistas que ignoravam uma pretensa "forma" em favor de um "conteúdo", que só podia ser ou "revolucionário", ou "reacionário" (STRADA, 1987, p. 151-217; ANDRADE, 2010, p. 152-165). Por outro lado, há que se considerar também o advento do new criticism, do close reading, e a hegemonia acadêmica das tendências pós-estruturalistas que já se faziam sentir em meados da década de 1960, o que, de algum modo, também fazia o pêndulo da história da crítica avançar

7 Lukács, sobretudo a partir de sua fase marxista, ficou conhecido como o crítico realista de esquerda mais eminente, cf. Lukács, 2010, p. 11-38, e também Eagleton, “Lukács e a forma literária" (2011, p. 55-62). Sobre crítica realista, cf. Waizbort, 2007. 
com ímpeto sentido contrário à tendência anterior. Candido, com sua formação sociológica devidamente construída na tradição do ensaísmo, sugere somente uma defesa de um ponto de equilíbrio entre os extremos combativos e bulhentos.

Evidentemente a proposta teórica feita por Candido, ao menos nos termos em que está formulada, fricciona com outras possibilidades de abordagem teórica menos preocupadas com o equilíbrio entre tendências e mais voltadas à compreensão da literatura enquanto um produto social in totum. Raymond Williams, por exemplo, no seu célebre ensaio "Base e superestrutura na teoria cultural marxista" (WILLIAMS, 2011, p. 43-68), em busca de uma definição para uma teoria cultural materialista, tem sua égide na afirmação primeira de Marx, de que o ser social determina a consciência ${ }^{8}$. Ao tomar essa afirmação como princípio, Williams procura relacioná-la com a problemática da infraestrutura e da superestrutura na tradição marxista que, em momentos mais ortodoxos, chegou a entrar em franca contradição com o princípio materialista formulado por Marx. O ponto nevrálgico, como discorre Williams, é sempre a relação de determinação entre as circunstâncias materiais e as formulações superestruturais, que pode ou assumir um significado de relação causal teleológica de cunho mecanicista entre duas ordens distintas em que uma ordem anterior prefigura a posterior de modo previsível, ou também, como Williams prefere, pode assumir o significado de "impor limites e exercer pressões, seja por alguma força externa ou por leis internas de um desenvolvimento particular" (WILLIAMS, 2010, p. 44; 2003, p. 103-107; 1979, p. 79-92).

Ao fazer a análise crítica dos termos consagrados pela tradição marxista para definir o trânsito das forças entre as condições econômicas materiais e as atividades humanas, Williams experimenta conceitos, relativiza-os, abandona alguns e faz novas propostas. Assim ocorre com 8 Trata-se de célebre afirmação de Marx em A ideologia alemã, de 1846: "A produção das ideias e representações, da consciência, aparece a princípio diretamente entrelaçada à atividade material e ao intercâmbio material dos homens, como a linguagem da vida real. [...] Os homens são os produtores de suas representações, das suas ideias etc. - mas se trata de homens reais e ativos, condicionados por um determinado desenvolvimento das suas forças produtivas e pelo intercâmbio a ele correspondente, inclusive suas formas mais desenvolvidas", in: Marx; Engels, 2010, p. 99. 
a "totalidade" lukacsiana, que, se por um lado busca abranger a um tempo base e superestrutura, por outro pode perder a força do dado intencional e de dominação no interior do conceito. Por isso Williams bebe em Gramsci o conceito de hegemonia, que abrange a um tempo a dominação, o conjunto de valores e significados dominantes e eficazes numa sociedade, as forças produtivas que ele controla e as formações culturais que exclui (culturas residuais e emergentes) ou que coopta, pelo processo de incorporação. Ao localizar a literatura e a arte diante deste quadro teórico assim formulado, Williams emite um juízo sobre a prática crítica que nos deve ser bastante elucidativo ao compará-lo com a prática teórica de Antonio Candido. A ver:

Agora, se voltarmos à questão cultural na sua forma mais usual - quais são as relações entre arte e sociedade, ou entre literatura e sociedade? - à luz da discussão anterior, temos de dizer, em primeiro lugar, que não há relações entre literatura e sociedade nessa forma abstrata. A literatura apresenta-se desde o início como uma prática na sociedade. De fato, até que ela e todas as outras práticas estejam presentes, a sociedade não pode ser vista como completamente formada. A sociedade não está totalmente disponível para análise até que cada uma das suas práticas esteja incluída. Mas ao adotarmos essa ênfase, devemos adotar uma outra correspondente: que não podemos separar a literatura e a arte de outros tipos de prática social de modo a torná-las sujeitas a leis muito especiais e distintas. Elas podem ter características bastante específicas como práticas, mas não podem ser separadas do processo social geral (WILLIAMS, 2010, p. 61).

Em vista do mesmo pêndulo da história da crítica literária, ora voltado em demasia para os "aspectos sociais", ora voltado em demasia para "aspectos formais", Williams encontra o seu ponto de equilíbrio através de um argumentum a fortiori: destrói o pêndulo e dilui a variação entre os extremos. Uma vez que sua formulação teórica está 
calcada no conceito de uma hegemonia ativa que abarca a um tempo desde o conjunto dos valores simbólicos até as forças produtivas, ergo literatura e sociedade são uma só dimensão composta de modo polimorfo e recíproco. A dicotomia entre "mais social" ou "mais formal" não pode então persistir numa crítica atenta uma vez que literatura e sociedade são complementares uma à outra, e, incluída num conjunto de práticas sociais distintas, a literatura obedece a "leis" que são homólogas, apesar das especificidades de características enquanto "práticas". É evidente que a diferença, assim posta, entre a formulação teórica de Williams e de Candido é flagrante. No entanto, quando analisamos a formulação teórica do crítico brasileiro, enfatizamos mesmo que existia um princípio de diluição entre os polos da dicotomia que se encontrava na conclusão da sua análise. Ainda, pois, que a formulação teórica de Candido seja discrepante da percepção da literatura como uma prática social conforme formulada por Williams, não nos parece, no entanto, que na prática da crítica a visão do crítico brasileiro não se conduza pela mesma noção da literatura como prática social.

É preciso lembrar aqui de um conjunto de ensaios de Candido que escapam ao escopo da crítica literária específica para a elaboração de "panoramas" que só são compreensíveis através de dinâmicas próprias da vida cultural assim como se encontram no interior de dinâmicas sociais - assim formuladas, assumem a forma de dissertações ensaísticas sobre a literatura de um ponto de vista da sociologia histórica da cultura. A coletânea de ensaios A educação pela noite, lançada no ano de 1987, contém uma série de textos emblemáticos desse estilo ensaístico, aos quais Antonio Candido, na sua "Explicação" que antecede o volume, define como "crítica esquemática", que seriam "panoramas abrangendo segmentos amplos da atividade literária e cultural vista a voo de pássaro" (CANDIDO, 2011, p. 10). Os ensaios incluídos no escopo dessa chamada "crítica esquemática" são quatro: "Literatura e subdesenvolvimento", "Literatura de dois gumes", "A Revolução de 1930 e a cultura", "A nova narrativa". Em "Literatura e subdesenvolvimento", Candido está preocupado com a questão da dependência 
da vida cultural latino-americana em relação à centralidade europeia, o que determina um encadeamento por "influência" hegemônica entre as literaturas sul-americanas e as europeias. Segundo o ensaísta, as literaturas americanas (em geral) seriam "basicamente galhos da metropolitana9". Para chegar a isso, no entanto, Candido desenha um terrível quadro apocalíptico do cenário cultural latino-americano caracterizado, sobretudo, pelo que chama de "debilidade cultural". Trata-se de uma série de fatores que serviam para piorar as condições de circulação da literatura nos países subdesenvolvidos sul-americanos; além do "analfabetismo", principal agravante de isolamento da literatura a um público ínfimo relativamente ao todo da população, somar-se-iam:

[...] falta de meios de comunicação e difusão (editoras, bibliotecas, revistas, jornais); inexistência, dispersão e fraqueza dos públicos disponíveis para a literatura, devido ao pequeno número de leitores reais (muito menor que o número já reduzido de alfabetizados); impossibilidade de especialização dos escritores em suas tarefas literárias, geralmente realizadas como tarefas marginais ou mesmo amadorísticas; falta de resistência ou discriminação em face de influências e pressões externas. $O$ quadro dessa debilidade se completa por fatores de ordem econômica e política, como os níveis insuficientes de remuneração e a anarquia financeira dos governos, articuladas com políticas educacionais ineptas ou criminosamente desinteressadas (Ibid., p. 172).

Malgrado certa perspectiva desenvolvimentista que percebe o subdesenvolvimento como uma etapa "ainda não solucionada" (Ibid., p. 173), e certa problematização da própria cultura centralizada demais na cultura erudita, revelando um suave desprezo pela cultura de massas e pelas culturas não-eruditas ditas "populares" (as culturas "residuais" e "emergentes" na terminologia de Williams), consideradas uma "eta9 Essa metáfora botânica é antiga na escrita de Candido: já estava no prefácio da $1^{\text {a }}$ edição de Formação da literatura brasileira: "A nossa literatura é galho secundário da portuguesa, por sua vez arbusto de segunda ordem no jardim das Musas...” (2013, p. 11). 
pa folclórica de comunicação oral" sem considerações na ordem dos intercâmbios entre essas diferentes esferas da cultura (Ibid., p. 174, cf. também Williams, 1992), o ensaio de Candido parece estar absolutamente de acordo com a necessidade de compreender os processos sociais nos quais a literatura circula como um bem simbólico ${ }^{10}$ como uma reflexão fundamental para a compreensão de aspectos relevantes dessa produção estética. Não parece aqui que o termo "sociedade" possa significar, no interior da reflexão de "Literatura e subdesenvolvimento", uma dimensão objetiva externa e alheia ao texto literário.

Suas reflexões acerca da dependência das literaturas não europeias escritas em línguas de origem europeia, inclusive, estão mesmo em condições de concordar com trabalhos mais voltados a uma sociologia da literatura, como em A república mundial das letras, da francesa Pascale Casanova (2002). Neste trabalho, a crítica francesa procura extrapolar uma noção de "mercado de bens simbólicos" para uma configuração planetária, um "mundo literário" (Ibid., p. 40), com suas próprias fronteiras, capitais e leis não necessariamente homólogas às homônomas do mundo político e econômico (Ibid., p. 25). Segundo Casanova, Paris se encontraria como capital funcional dessa estrutura literária, uma capital desnacionalizada e agregadora, em franca disputa com diversos outros centros. Esses outros centros podem ser definidos justamente a partir de "territórios linguísticos" que são expressões atuais de um passado colonial: "emanação e a materialização da dominação política e linguística” (Ibid., p. 150). Há que se questionar o galiocentrismo de Casanova, mas a consciência da dependência intelectual causada pelo subdesenvolvimento cultural do universo pós-colonial já estava muito bem pressentido por Candido, e desde muito tempo.

Afinal, no aparato metodológico de Formação da literatura brasileira (2013), sua magnum opus, já estava presente a ideia de que a literatura brasileira só se "forma" a propósito de um "empenho" que se realiza 10 Candido não utiliza o termo "bem simbólico" neste ensaio nem tampouco apresenta ecos relevantes das teorias simbólicas da sociologia em sua obra, senão eventuais semeIhanças e proximidades relevantes, reveladas pela pesquisa empírica, ou, como ele próprio diz: "Eu cheguei a conclusão parecida [com a teoria de Mannheim] por via puramente empírica, como é do meu feitio...", (Jackson, 2002, p. 33). 
através da acumulação literária de uma tradição - ou seja, para compreender a formação de qualquer manifestação a que se convencione chamar de "literatura brasileira" é preciso avaliar a dinâmica que se estabelece entre obras ao longo do tempo, ou, melhor dizendo, interpretar a literatura de modo "sistêmico". A concepção prática de que lança mão para analisar o processo formativo, descrita na conhecida introdução à obra, o "sistema literário", diferente de "manifestações literárias", nada mais era do que uma concepção social-comunicativa da literatura enquanto "sistema simbólico, por meio do qual as veleidades mais profundas do indivíduo se transformam em elementos de contacto entre os homens" [sic] (Ibid., p. 25). Assim sendo, o sistema literário só estaria definitivamente formado quando houvesse a completa conjugação de diversos elementos, não necessariamente estéticos, a saber:

Entre eles se distinguem: a existência de um conjunto de produtores literários, mais ou menos conscientes do seu papel; um conjunto de receptores, formando os diferentes tipos de público, sem os quais a obra não vive; um mecanismo transmissor, (de modo geral, uma linguagem, traduzida em estilos), que liga uns a outros (Ibid., id.).

Quando ocorre a formação do sistema e a consequente passagem do tempo garante a integração de novos grupos e escritores ao mesmo sistema, existe a "formação da continuidade literária", a construção de uma tradição, que garante a formação de padrões dominantes que se impõem às dinâmicas culturais de um momento, reconhecíveis pela crítica. Candido esclarece, portanto, que seu esforço crítico, direcionado a compreender essa dinâmica histórica formativa (que ele chama de "crítica histórica"), não poderia isolar a abordagem à obra numa autonomia que a abstraísse dessas circunstâncias, mas, em Formação da literatura brasileira, as obras aparecem, antes "integrando em dado momento um sistema articulado e, ao influir sobre a elaboração de outras, formando, no tempo, uma tradição" (Ibid., p. 26). 
Ora, a argumentação que temos tentado perseguir até aqui é que uma trajetória intelectual profícua, muitíssimo longeva e altamente investigativa como a de Antonio Candido não poderia ter produzido e não produziu conceitos teóricos fechados e coesos, verificáveis de igual modo em toda a sua produção, e que, portanto, poderiam ser descolados dos objetos empíricos dos quais ele lança mão e aplicados a esmo a quaisquer contextos outros. Para isso tomamos três estilos distintos de sua produção cunhados por ele próprio: um ensaio "empenhado teoricamente", uma "crítica esquemática" e uma "crítica histórica" e buscamos precisamente enfatizar a discrepância que existe entre as diversos valores e funcionalidades que o termo "sociedade" assume em objetos específicos desses diferentes estilos de ensaios. Evidentemente, restam outros estilos de ensaios praticados por Candido que não contemplamos aqui: o do tipo que ele chama de "crítica de vertentes", aquela que está despreocupada com interesses prévios mas é "ajustável à natureza da obra", "seguindo o pendor natural do objeto" (2010, p. 12); ou mesmo o tipo de ensaio praticante da tão famigerada "redução estrutural". Novamente, apesar de nas formulações sobre a redução estrutural que manifestam esboços teóricos de Candido o termo sociedade ser cambiável por "realidade", objetiva e "externa", sua prática na crítica é mais complexa (Ibid., p. 10). Roberto Schwarz busca perseguir a fluidez dessa tal redução estrutural no ensaio "Dialética da malandragem" (Ibid., p. 17-42) de Antonio Candido, num tipo de escrita inusitada, um ensaio crítico de outro ensaio crítico (SCHWARZ, 1987, p. 129-155). Um pouco na tentativa de dizer sobre a redução estrutural aquilo que ela própria não afirma, mas pratica, um pouco expondo sua metodologia que compreendemos, mas cuja esquematização é complexa, Schwarz afirma sobre a dualidade entre literatura e sociedade (talvez hiperinterpretando o mestre):

À parte os resultados, a originalidade de "Dialética da malandragem" não está no desejo de ligar literatura e sociedade, que afinal de contas é comum. Está na firmeza com que An- 
tonio Candido se deixa guiar pelo discernimento formal, seja para discriminar as componentes de fatura do livro e estabelecer sua organização, seja para buscar o seu correlato social, que será construído para explicar a forma. Se a crítica de orientação sociológica omite a forma literária e usa os dados da ficção como se fossem documentos da realidade (questões formais são fantasia, como quer o viés antiestético do espírito positivo), estamos nos seus antípodas (Ibid., 1987, p. 144).

Não há dúvidas, no entanto, quanto ao fato de que toda a obra de Antonio Candido, em sua imensa variedade de estilos, de intenções, de abordagens e de objetos, apresenta como ponto de fuga o desejo de mergulhar no conhecimento e explicação da sociedade brasileira para a qual a literatura brasileira sempre foi um instrumento de construção, descoberta e interpretação, para emular sua expressão (Candido utiliza a expressão para o surgimento da prosa de ficção no séc. XIX, cf. CANDIDO, 2013, p. 429-437). Esse vício de interpretação da experiência social e da acumulação cultural brasileira (denomine-a ele como preferir) a partir da literatura na obra do professor só pode ser definitivamente apreendido se consideradas todas as dinâmicas e estruturas formativas de sua própria constituição como intelectual, sua "posição no campo intelectual", para citar Pierre Bourdieu (2009, p. 154; 1996, p. 261-265). Criado no entroncamento de diversas gerações que tiveram como missão perscrutar o Brasil e que desaguou no alvorecer da inteligência intelectual crítica do país, Candido é muito fruto de seu tempo, que é ainda o nosso, e precisa ser visto em toda a força de seus alcances e empenhos e em todas as fronteiras de seus limites e contradições.

\section{REFERÊNCIAS BIBLIOGRÁFICAS}

ANDRADE, Homero Freitas de. O realismo socialista e suas (in)definições. In: Literatura e sociedade, São Paulo, DTLLC, FFLCH - USP, nº 13, 2010. 
ARANTES, Paulo; ARANTES, Otília Fiori. O sentido da formação. Rio de Janeiro: Paz e Terra, 1997.

ARRUDA, Maria Arminda do Nascimento. A sociologia no Brasil: Florestan Fernandes e a "escola paulista". In: MICELI, Sérgio (org.). História das Ciências Sociais no Brasil, v. 2. São Paulo: Sumaré, 1995.

BOURDIEU, Pierre. A economia das trocas simbólicas. São Paulo: Perspectiva, 2009.

literário. São Paulo: Cia. das Letras, 1996.

- As regras da arte: gênese e estrutura do campo CANDIDO, Antonio. A educação pela noite. Rio de Janeiro: Ouro sobre azul, 2011.

Unesp, 1992.

. Brigada ligeira e outros escritos. São Paulo: Ed.

. Formação da literatura brasileira: momentos decisivos. Rio de Janeiro: Ouro sobre azul, 2013.

. Introdução. In: BASTIDE, Roger. Poetas do Brasil. São Paulo: Edusp; Duas Cidades, 1997.

- Literatura e sociedade: estudos de teoria e história literária. Rio de Janeiro: Ouro sobre azul, 2008.

. O discurso e a cidade. Rio de Janeiro: Ouro sobre azul, 2010.

sobre azul, 2010.

. Os parceiros do Rio Bonito. Rio de Janeiro: Ouro - Vários escritos. São Paulo: Duas cidades, 1970.

CASANOVA, Pascale. A república mundial das letras. São Paulo: Estação Liberdade, 2002.

COSTA, Iná Camargo. Entrevista sobre a obra de Antonio Candido. Literatura e Sociedade, São Paulo, DTLLC, FFLCH, USP, nº 11, 2009.

DANTAS, Vinícius. Bibliografia de Antonio Candido. São Paulo: Editora 34 / Duas Cidades, 2002.

EAGLETON, Terry. Marxismo e crítica literária. São Paulo: Ed. Unesp, 2011. 
JACKSON, Luiz Carlos. O Brasil dos caipiras. Literatura e Sociedade, São Paulo, DTLLC, FFLCH, USP, nº 12, 2009.

. A tradição esquecida: Os parceiros do Rio Bonito e a sociologia de Antonio Candido. Belo Horizonte: Ed. UFMG, 2002. LUKÁCS, Györg. Introdução aos escritos estéticos de Marx e Engels. In: MARX, Karl; ENGELS, Fredrich. Cultura, arte e literatura: textos escolhidos. São Paulo: Expressão Popular, 2010.

MARX, Karl; ENGELS, Fredrich. Cultura, arte e literatura: textos escolhidos. São Paulo: Expressão Popular, 2010.

PONTES, Heloísa. Destinos mistos: os críticos do Grupo Clima em São Paulo 1940-1968. São Paulo: Cia. das Letras, 1998.

STRADA, Vittorio. Do "realismo socialista" ao zdhanovismo. In: HOBSBAWM, Eric (Org.). História do Marxismo V. IX; o marxismo na época da terceira internacional: problemas da cultura e da ideologia. Rio de Janeiro: Paz e Terra, 1987.

SCHWARZ, Roberto. Ao vencedor as batatas: forma literária e processo social nos inícios do romance brasileiro. São Paulo: Editora 34 / Duas Cidades, 2012.

. Entrevista sobre a obra de Antonio Candido. Literatura e Sociedade. São Paulo, DTLLC, FFLCH, USP, n 11, 2009

- Pressupostos, salvo engano, de "Dialética da malandragem". In: Que horas são? Ensaios. São Paulo: Cia. das Letras, 1987.

WAIZBORT, Leopoldo. A passagem do três ao um: crítica literária, sociologia, filologia. São Paulo: CosacNaify, 2007.

WILLIAMS, Raymond. Cultura. Rio de Janeiro: Paz e Terra, 1992. . Cultura e materialismo. São Paulo: Ed. Unesp, 2011.

- Marxismo e literatura. Rio de Janeiro: Zahar,

1979.

sociedad. Buenos Aires: Nueva Vision, 2003.

. Palabras clave: un vocabulario de la cultura y la 